\title{
MODELO DE AVALIAÇÃO DE DESEMPENHO ORGANIZACIONAL PARA PEQUENAS E MÉDIAS EMPRESAS
}

\section{RESUMO}

A partir dos anos 1980, muitas ferramentas para avaliação de desempenho organizacional foram criadas. No entanto, muitas delas atendem somente às grandes empresas e não fomentam resultados nas pequenas e médias empresas. Diante disso, esse artigo tem como objetivo propor um modelo de Avaliação de Desempenho Organizacional (ADO) no qual seja flexível e adaptável à realidade das PMEs, partindo-se do referencial teórico de diversos modelos e suas respectivas comparações com base nos critérios de três importantes autores para avaliação de ADO. A pesquisa tem caráter descritivo e exploratório, com natureza qualitativa. O Modelo MADE-O foi o modelo, que segundo os critérios descritos na bibliografia, melhor se enquadrou para as necessidades das PMEs, tendo sido utilizado como base para a criação da proposta de modelo apresentado neste estudo, com adaptações do modelo BSC. O Modelo chamado de Indicador de Desempenho Global - Enviroment (IDG-E) tem como principal diferencial, além da base dos modelos citados anteriormente, a avaliação do ambiente externo e interno com pesos ponderados nos módulos de ADO. Como a PME é caracterizada por ter poucos processos e pessoas, a pequena quantidade de indicadores de desempenho é outro aspecto positivo. Submetido à avaliação dos critérios apresentados pelos autores, o modelo se mostrou bastante factível para uso nas PMEs.

Palavras-chave: Avaliação de Desempenho Organizacional; Pequenas e Médias Empresas; Planejamento; Gestão Flexível; Gestão Adaptável.

\section{EVALUATION MODEL OF ORGANIZATIONAL PERFORMANCE FOR SMALL AND MEDIUM ENTERPRISES}

\begin{abstract}
In the 1980's, many tools for evaluating organizational performance were created. However, most of them are useful only to large companies and do not foster results in small and medium-sized enterprises (SMEs). In light of this fact, this article aims at proposing an Organizational Performance Assessment model (OPA) which is flexible and adaptable to the reality of SMEs, based on the theoretical framework of various models, and comparisons on the basis of three major authors' criteria to evaluate OPA models.

The research has descriptive and exploratory character, with qualitative nature. The MADE-O model, according to the criteria described in the bibliography, is the one that best fits the needs of SMEs, used as a baseline for the model proposed in this study with adaptations pertaining to the BSC model. The model called the Overall Performance Indicator - Environment (IDG-E) has as its main differential, in addition to the base of the models mentioned above, the assessment of the external and internal environment weighted in modules of OPA. As the SME is characterized by having few processes and people, the small amount of performance indicators is another positive aspect. Submitted to the evaluation of the criteria subscribed by the authors, the model proved to be quite feasible for use in SMEs.
\end{abstract}

Keywords: Evaluation of Organizational Performance; Small and Medium Enterprises; Planning; Management; Flexible; Adaptable. 


\section{MODELO DE EVALUACIÓN DEL DESEMPEÑO ORGANIZACIONAL PARR PEQUEÑAS Y MEDIANAS EMPRESAS}

\section{RESUMEN}

Desde los años 1980 se crearon Del Parr Muchas herramientas de medida del desempeño de la organización. Sin embargo, muchos de ellos se dedican sólo a las grandes empresas y no fomentan resultados en Pequeñas y Medianas Empresas. Diso antes, este artículo se propone un PROPORCION ADO Plantilla en el cual es flexible y adaptable a la realidad de las PYME, a partir de Haga referenciales diversos modelos teóricos y sus comparaciones con ella sobre la base de criterios de tres importantes autores revisión Parr de ADO. Una investigación es exploratoria y descriptiva, y es literatura. Y en su naturaleza de relaciones de la ONU, es cualitativo, sea o Una implican la recogida de una gran variedad de materiales empíricos, estudios de casos, experiencias personales, entre otras cosas. HIZO el modelo al que fue el modelo que, según el criterio de tres diferentes autores, SI mejor enmarca como requisitos Parr de las PYME. Para diso cuenta, fue utilizado como base para la creación del modelo HACER propuesta presentada en este estudio, con ajustes a los modelos de BSC. El modelo llamado Indicador de Desempeño Global - Enviroment ( IDG- E) tiene CÓMO diferencial Además de la base principal de los modelos mencionados anteriormente, HACER revisión Una entorno externo e interno con los pesos en módulos ADO ponderados. Cómo ONU PYME se caracteriza Porción tienen menos procesos y personas, se unen pequeña cantidad de indicadores de desempeño es otro aspecto positivo. Enviado a revisión de los criterios presentados por los tres autores, el modelo mostró En Si Muy factible Parr USO PYME.

Palabras-clave: Evaluación del Desempeño de las Organizaciones; Pequeñas y Medianas Empresas; Planificación; Gestión; Flexible; Adaptable.

\footnotetext{
${ }^{1}$ Doutorando em Administração pela Faculdade de Economia, Administração e Contabilidade da Universidade de São Paulo - FEA/USP. Professor auxiliar na Faculdade de Economia, Administração e Contabilidade da Universidade de São Paulo - FEA/USP. Brasil. E-mail: carlospassos@ usp.br

${ }^{2}$ Doutora em Administração pela Universidade de São paulo - USP. Professora da Faculdade de Economia, Administração e Contabilidade da Universidade de São Paulo - FEA/USP. Brasil. E-mail: renatag@fia.com.br
} 


\section{INTRODUÇÃO}

A Avaliação de Desempenho Organizacional (ADO) tem sido objeto de vários estudos, principalmente a partir de 1980 (Garengo, Biazzo \& Bititci, 2005). "Diversas ferramentas foram desenvolvidas com o objetivo de avaliar o desempenho organizacional" (Bortoluzzi, Vicente, S. Ensslin \& L. Ensslin, 2009).

Garengo et al. (2005), justificam com base na literatura, que boa parte das ferramentas criadas para avaliar o desempenho organizacional foca-se em grandes empresas e que por melhor uso que possam ter, não atendem de forma adequada as características diferenciadas das Pequenas e Médias Empresas (PMEs). Ainda, apontam que a escassez de recursos humanos e de capital; a falta de planejamento estratégico e a não compreensão das vantagens desses sistemas como outros motivos para a não adoção da ADO.

"Muitos trabalhos têm focado as pequenas empresas com o objetivo de entender suas especificidades (Leone, 1999; Escrivão Filho, 1995; Welsh, White, 1981; Inácio Júnior, 2008; Ricci, 2010)" citados por Ricci e Escrivão Filho (2010).

"Esses estudos mostram que as especificidades das pequenas empresas exercem forte influência na gestão e fazem com que elas ignorem o planejamento, sendo assim necessária a adequação entre esta técnica e as especificidades delas" (Almeida, 1994 citado por Ricci \& Escrivão Filho, 2010).

Diante disso, o objetivo desse artigo é propor um modelo de indicador de ADO flexível que possa ser adaptado às características das PMEs, partindo da avaliação ponderada do ambiente interno pelo ambiente externo por meio da utilização de cenários.

Essa avaliação ponderará as principais ações internas do administrador de forma estratégica permitindo um olhar de diagnóstico cruzado de fora e de dentro da organização, estudado na abordagem contingencial. Para isso, foi desenvolvido um questionário com informações do macro ambiente e do ambiente setorial da organização e seus impactos contingenciais no ambiente interno da organização.

\section{FUNDAMENTAÇÃO TEÓRICA}

\subsection{Conceitos e Elementos de Avaliação de Desempenho Organizacional (ADO)}

Dutra (2003) afirma que o ato ou ação de gerenciar uma organização requer um processo de avaliação de seu desempenho, mesmo que seja informal, pois a melhoria do desempenho da organização passou a ser o ponto focal de todos os profissionais que tomam decisões, dessa forma, é imperativa a adoção de sistemas de avaliação nos dias atuais.

Segundo Corrêa (1986), ADO avalia o desempenho da organização incluindo todas as variáveis/dimensões que afetam a consecução dos objetivos e, consequentemente, o desempenho organizacional. "Além disso, um sistema de avaliação de desempenho deve integrar as diferentes dimensões para que todas estejam consoantes com os objetivos organizacionais. Portanto, um sistema de ADO deve estabelecer uma análise da organização de forma global de maneira a integrar todas as perspectivas relevantes da organização" (Sinclair \& Zairi, 2000, citados por Cunha, 2011).

Bortoluzzi et al. (2009) consideram que os artigos estudados por eles não apresentam um conceito objetivo de ADO e também não apresentam uma afiliação teórica. $\mathrm{O}$ que os autores abordam são entendimentos sobre $\mathrm{ADO}$, que são encontrados no decorrer da leitura dos textos. O entendimento que pode ser encontrado no decorrer de todos os artigos analisados é a necessidade de se elaborarem medidas de desempenho que considerem aspectos financeiros e não financeiros.

Para Nørreklit (2000) haverá sempre algum aspecto de subjetividade na avaliação de desempenho, cujo efeito dependerá mais da intuição dos administradores, na medida em que assumam premissas baseadas nessa intuição.

Um bom modelo de ADO para Garengo et al. (2005) deve ter: Alinhamento estratégico, isto é, o sistema de Avaliação de Desempenho deve assegurar que as medidas adotadas são coerentes com a estratégia; Desenvolvimento da Estratégia, ou seja, ajuda a desenvolver os objetivos e estratégias prédefinidas; Foco nos Stakeholders, os sistemas de ADO devem atender aos diversos grupos de interesses; Medidas Financeiras e Não Financeiras, isto é, os sistemas de Avaliação de Desempenho devem fazer uso de medidas financeiras e não financeiras; Adaptabilidade Dinâmica, pois os sistemas de ADO devem reagir rapidamente às mudanças nos contextos internos e externos; Orientado por Processo, pois a organização não é vista como uma estrutura hierárquica, mas como um conjunto coordenado de processos; Profundidade e Detalhamento, ou seja, as medidas de desempenho são desenvolvidas em profundidade e abrangem com detalhes todas as áreas organizacionais; Abrangência, onde toda a organização é objeto de avaliação; Relacionamento de causa e efeito para verificar se existe relação entre os objetivos estratégicos e os operacionais; e, por fim, Clareza e Simplicidade, ou seja, ao fixar objetivos e medidas de desempenho, a metodologia deve ser simples e clara para comunicar a todos os envolvidos.

Para Corrêa (1986), uma ADO deve responder às seguintes perguntas: Para que? (utilidade); Para quem? (usuários); $\mathrm{O}$ que? (dimensões/variáveis); 
Como? (fases do modelo); Quem? (responsabilidades); Quando? (frequência da aplicação). Além disso, "para ser caracterizada como um Modelo de ADO completo ele deve possuir 5 características": ser global e contemplar todas as dimensões; ter histórico de vários anos; ser comparativo em relação a outras empresas e setores como benchmarking; ter relação de causa e efeito e; se antecipar, ou seja, buscar a origem das causas (Corrêa, 1986).

Na avaliação de Dutra (2003) os principais modelos de ADO e suas dimensões devem ter: Grau de Personalização, que identifica a potencialidade em atender as necessidades específicas de uma organização em particular; Grau de Ambiguidade, que identifica se a estrutura metodológica apresenta a possibilidade de mais de uma forma de interpretação ou de duplo sentido; Grau de Priorização, que identifica se a metodologia enfatiza ou desconsidera certas medidas de desempenho ou áreas da organização, em detrimento de outras, dando importância excessiva a algum indicador ou aspecto específico; Grau de Flexibilidade, que identifica o grau de flexibilidade para atender a qualquer tipo de organização, considerando sua estrutura organizacional; Grau de Geração de Conhecimento, que identifica se no decorrer da implementação da metodologia ocorre a conscientização, envolvimento e responsabilidade dos indivíduos de forma cognitiva e não apenas por ação de treinamento; Grau de Geração de Aperfeiçoamento, que identifica se a metodologia permite a geração de aperfeiçoamento do desempenho organizacional em decorrência da identificação dos pontos fracos.

\subsection{Principais Metodologias de ADO Analisadas Neste Estudo}

\subsubsection{Modelo Corrêa - Modelo de Avaliação de Desempenho Organizacional (MADE-O)}

O modelo propõe um método de avaliação descritivo que reúne informações gerais da empresa, como sua filosofia empresarial, seus objetivos e missão. O modelo define também quais serão os módulos ou áreas em que a empresa será dividida para a avaliação. Levanta os principais indicadores de cada módulo: identificação, seleção, hierarquização e metodologia de levantamento de dados. Definição dos padrões de desempenho, por meio de benchmarking interno e externo, além de considerar as contingências próprias da organização e ambientais. O modelo traz também a avaliação e feedback cuja missão é comparar o desempenho atingido ao desempenho desejado, buscando, para os indicadores uma possível revisão e mudança em sua hierarquização. Além disso, o modelo traz o estabelecimento de relações de causa e efeito para as variáveis de desempenho, possibilitando a sua correção e melhoria.

\subsubsection{Performance Measurement System for Service Industries (PMS)}

Também chamado de Quadro de Resultados e Determinantes por causa de sua particular atenção à relação entre os resultados e determinantes. Em particular, este modelo concentra-se em seis dimensões divididas em resultados (competitividade, desempenho financeiro) e os determinantes destes resultados (qualidade de serviço, flexibilidade, utilização de recursos e inovação). Sublinha a importância de definir cuidadosamente os indicadores de desempenho necessário para atingir o objetivo de desempenho. Este modelo apresenta uma relação estreita entre PMS, estratégia e competitividade. Foi desenvolvido apenas para as empresas de serviços (Fitzgerald et al., 1991; Fitzgerald \& Moon, 1996 citados por Garengo et al., 2005).

\subsubsection{Balanced Scorecard (BSC)}

"O Balanced Scorecard é um modelo bastante conhecido, que tem atraído muita atenção de profissionais e acadêmicos" (Nørreklit, 2000).

De acordo com Kaplan e Norton (1997) o Balanced Scorecard é um instrumento capaz de integrar as medidas financeiras da organização, abrangendo perspectivas do cliente da organização, dos processos internos, do aprendizado e do crescimento.

Nørreklit(2000) citando Haas e Kleingeld (1999) explica que o diferencial do modelo está nos relacionamentos de causa-e-efeito entre as medidas de resultados e os condutores deste resultado de desempenho. Além disso, o Balanced Scorecard deve ser capaz de alinhar objetivos departamentais e objetivos pessoais à estratégia global da organização (Kaplan \& Norton, 1996).

De acordo com Kaplan e Norton (1997), o Balanced Scorecard equilibra os objetivos de curto e de longo prazo, os resultados desejados, os vetores desses resultados e medidas concretas em quatro perspectivas: Financeira, Clientes, Processos Internos e Aprendizagem e Renovação.

\subsubsection{Integrated Performance Measurement System (IPMS)}

Bititci et al. (1997) citados por Garengo et al. (2005) definiram o Sistema Integrado de Medição de Desempenho (IPMS) como um modelo que promove a integração de várias partes da empresa e a implantação dos objetivos e políticas de negócio em quatro níveis com interesse do nível superior sobre os níveis inferiores. O modelo é baseado em quatro níveis (corporativo, unidades de negócios, processos de negócios e atividades). Ainda, para cada nível cinco fatores-chave são considerados (partes interessadas, critérios de controle, medidas externas, objetivos de melhoria e medidas internas). 
Modelo de Avaliação de Desempenho Organizacional para Pequenas e Médias Empresas

\subsubsection{Organizational Performance Measurement (OPM)}

Desenvolvido para apoiar ADO em PMEs, o modelo é baseado em três princípios: alinhamento, onde as medidas de desempenho selecionadas apoiam o alinhamento das pessoas à estratégia da empresa; processo de pensamento, onde o sistema se refere ao controle de monitoramento de processo e seu sistema de melhoria; e praticidade, onde em qualquer nível da empresa há um processo consistente de escolha de medidas para garantir a qualidade e adequação dos dados. O quadro é baseado em dois construtos chave de gestão: Zona da gestão, que se refere às três zonas de gestão (estratégico, tático e operacional) de diferentes responsabilidades e autoridades; e Teoria de Sistemas Abertos, que se refere ao ambiente da empresa, utilizando-se a análise de satisfação das partes interessadas, cujo indicador no modelo é o mais importante (Chennell et al., 2000; citado em Garengo et al., 2005)

\subsubsection{Performance Prism (PP)}

Com base em um modelo tridimensional de mensuração de desempenho, a figura de um prisma representa a arquitetura de todo o modelo, onde cada fase representada no prisma corresponde a uma dimensão específica de análise (Neelyet al., 2002 citado em Garengo et al., 2005). As dimensões são as seguintes: Satisfação dos Stakeholders, Capacidades, Processos, Estratégias e Contribuição dos Stakeholders.

\subsubsection{Integrated Performance Measurement for Small Firms (IPMS)}

Laitinen (1996/2002) citado por Garengo et al. (2005) definiu o modelo como um sistema de contas hibrido que liga a visão tradicional e o custeio baseado em atividades juntos em uma cadeia causal. O modelo foi projetado especificamente para ser usado em PMEs e resulta de sete dimensões principais de medidas, classificadas como duas dimensões externas (desempenho financeiro e competitividade) e as cinco dimensões internas (custos, fatores de produção, atividades, produtos e receitas) ligados por uma cadeia causal. As dimensões de caráter externo monitoram a posição da empresa no ambiente competitivo e as dimensões externas são utilizadas para controlar o processo de produção.

\subsection{Análise Comparativa dos Modelos de ADO}

Diante da necessidade de atender a condições específicas das organizações, as metodologias de ADO seguem os preceitos e pressupostos de seus criadores. Uma consideração rápida desses pressupostos e características é suficiente para que se perceba a defasagem existente entre as propostas neles calcadas e o contexto organizacional da atualidade (Dutra, 2005).

Dessa forma, a Figura 1 traz os principais critérios de avaliação apontados na fundamentação teórica anteriormente descrita, como forma de ajudar na análise e escolha dos principais modelos que farão parte do modelo proposto.

\begin{tabular}{|c|c|c|c|c|c|c|c|c|}
\hline CRITÉRIOS & MODELOS & MADE-O & $P M S$ & $B S C$ & IPMS & $O P M$ & $P P$ & $I P M S F$ \\
\hline \multicolumn{9}{|l|}{ Dutra } \\
\hline Personalização & & (:) & 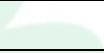 & $\oplus$ & $\odot$ & & (:) & -) \\
\hline Ambiguidade & & & & & & ;) & & \\
\hline Priorização & & & $\odot$ & 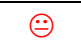 & & $\odot$ & & \\
\hline Flexibilidade & & (;) & & 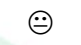 & (-) & & (:) & (-) \\
\hline Conhecimento & & (:) & & (:) & :- & & (-) & -) \\
\hline Aperfeiçoamento & & (;) & (:) & (;) & (:) & & & (2) \\
\hline \multicolumn{9}{|l|}{\begin{tabular}{|l|} 
Garengoet al. \\
\end{tabular}} \\
\hline Alinhamento & & (:) & (:) & (:) & $\oplus$ & $\odot$ & $\odot$ & \\
\hline Desenvolvimento & & (;) & (:) & (;) & (-) & & (:) & \\
\hline Stakeholders & & (i) & & & (i) & (-); & (-) & \\
\hline Medidas não financeiras & & (;) & (:) & (;) & (:) & (:) & (2) & (-) \\
\hline Adaptabilidade & & (;) & (;) & & (:) & & (2) & \\
\hline Orientação Processos & & (;) & & $\oplus$ & (-) & (:) & (-) & (-) \\
\hline Detalhamento & & (;) & (;) & (;) & (:) & (:) & (2) & $\odot$ \\
\hline Abrangência & & (i) & (:) & (i) & (-) & (-) & (-) & \\
\hline Causa / Efeito & & (-) & (-) & (-) & $\odot$ & & (-) & (-) \\
\hline
\end{tabular}


Modelo de Avaliação de Desempenho Organizacional para Pequenas e Médias Empresas

\begin{tabular}{|c|c|c|c|c|c|c|c|}
\hline Simplicidade & (:) & & & 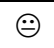 & $: ;$ & (:) & (:) \\
\hline \multicolumn{8}{|c|}{ Correia } \\
\hline Abrangente & (:) & :) & (:) & (); & (:) & (2) & \\
\hline Histórico & (2) & & & & & & \\
\hline Comparativo & (2) & $:-$ & & & & & \\
\hline Causa / Efeito & (); & (): & (:) & :) & & (:) & (;) \\
\hline Antecipação & (2) & (2) & (2) & $:-$ & & (2) & (:) \\
\hline
\end{tabular}

Atende Totalmente $\odot$ - Atende Parcialmente $\odot-;$ - Negativos $;(-)$

Figura 1 - Avaliação Crítica das Metodologias Apresentadas no Estudo

Pela análise da Figura 1, percebe-se que o modelo MADE-O (Corrêa, 1986) é o que considera todos os elementos de ADO o que o apresenta como um modelo robusto para o atendimento das PMEs. A ferramenta Performance Prism (PP) considera boa parte dos elementos, contudo, não atende ao requisito de aperfeiçoamento (Dutra, 2005), atende parcialmente o aspecto de alinhamento estratégico (Garengo et al., 2005; citado em Bortoluzzi et al., 2009) e não atende aos critérios histórico e comparativo (Corrêa, 1986). Conforme Bortoluzzi et al. (2009), as metodologias voltadas ao atendimento das PMEs como OPM e IPMSF apresentam diversas limitações. No primeiro modelo há o atendimento parcial do alinhamento estratégico, à clareza e simplicidade, todavia, não atende aspectos de alinhamento estratégico e também não se adapta rapidamente aos contextos internos e externos, além de não apresentar relação de causa e efeito entre os objetivos operacionais e estratégicos. No segundo modelo, não há o atendimento da maioria dos aspectos relacionados à $\mathrm{AD}$.

\subsection{Caracterização das Pequenas e Médias Empresas}

Várias são as definições pelo mundo relativas às Pequenas e Médias Empresas (PMEs) que, geralmente seguem a um propósito específico para estudiosos e para as instituições (Jamil \& Mohamed, 2011).

Uma revisão da literatura indicou que o número de funcionários que trabalham em uma empresa ou estabelecimento tende a ser um dos principais critérios utilizados na categorização tamanho das PMEs (Jamil \& Mohamed, 2011).

A Serasa Experian (2010), importante banco de informações de pessoa física e jurídica, utiliza outra classificação, que envolve, além da receita operacional das empresas, também o ativo total. Assim, empresas de pequeno porte, para a Serasa Experian, precisam ter faturamento líquido entre $R \$ 250$ mil e $R \$ 4$ milhões, além disso, ativo total entre $\mathrm{R} \$ 100$ mil e $\mathrm{R} \$ 4$ milhões. Para as médias empresas, tanto o faturamento quanto o ativo precisam ficar entre $R \$ 4$ milhões e $R \$ 25$ milhões.

Leone (1999) afirma que não é possível definir as PMEs com um único conceito, pois elas não têm o mesmo comportamento econômico e social, porém, conhecer mais profundamente suas especificidades ajuda a reduzir a alta taxa de mortalidade dessas organizações. Ainda, a autora divide as especificidades das PMEs em três grupos:

- Especificidades Organizacionais: Pobreza de recursos; Gestão centralizadora; Situação extra organizacional incontrolável; Fraca maturidade organizacional; Fraqueza das partes no mercado; Estrutura simples e leve; Ausência de um planejamento formal de trabalho; Fraca especialização; Estratégia intuitiva e pouco formalizada.

- Especificidades Decisionais: Tomada de decisão intuitiva; Horizonte temporal de curto prazo; Inexistência de dados quantitativos; Alto grau de autonomia decisória; Racionalidade econômica política e familiar.

- Especificidades Individuais: Onipotência do proprietário-dirigente; Identidade entre pessoa física e jurídica; Dependência perante certos funcionários; Influência pessoal do proprietário-dirigente; Simbiose entre patrimônio social e pessoal; Propriedade dos capitais; Propensão a riscos calculados.

\subsubsection{Eficiência Financeira das Pequenas e Médias Empresas}

Amaru (2005) explica que o desempenho de uma organização é aceitável ou satisfatório quando por meio da utilização correta dos recursos, todos os stakeholders ficam satisfeitos.

De acordo com Barret al.(2002) citado por Macedo, Silva e Santos (2006), "nas indústrias competitivas, as unidades de produção podem ser separadas em dois grupos distintos: eficientes e ineficientes, obedecendo a um padrão de avaliação de desempenho. Essas informações podem auxiliar numa análise de desempenho, pois são capazes de identificar melhores e piores práticas relacionadas com alta e a baixa eficiência".

O desempenho organizacional é convencionalmente definido em termos de suas 
Modelo de Avaliação de Desempenho Organizacional para Pequenas e Médias Empresas

características de output (produção, vendas etc.) ou de input (custos, gastos etc.) ou ainda como uma relação entre outputs e inputs (eficiência, produtividade etc.) (Meimand et al., 2002).

Recente estudo da Serasa Experian (2011) utilizando a técnica estatística de Análise Envoltória de Dados (DEA - Data Envelopment Analysis) criou o Indicador Serasa Experian de Eficiência Empresarial das Pequenas e Médias Empresas (IEE-PME). Esse indicador utiliza como fundamento o conceito de eficiência financeira utilizando como input do sistema os custos e as despesas operacionais (soma das despesas de vendas, administrativas e de depreciação) e como output do sistema receitas líquidas de vendas das empresas (faturamento após os impostos) e o resultado do exercício. Pode-se perceber por meio do estudo (Serasa Experian, 2011) que as PMEs registraram melhoria no nível médio de eficiência financeira nos últimos anos da análise, todavia, estiveram muito abaixo das organizações de capital aberto, benchmarking da pesquisa. A Figura 2 aponta para o nível de eficiência das PMEs vis a vis empresas de capital aberto.

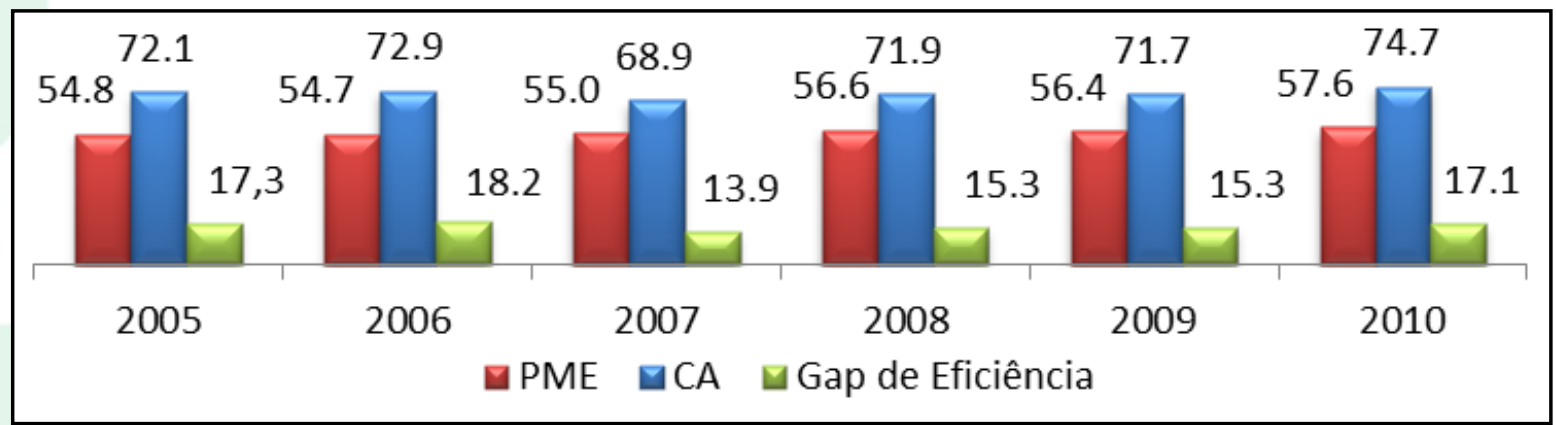

Figura 2 - Comparativo entre a Eficiência Empresarial das PMEs com as Empresas de Capital Aberto Fonte: Serasa Experian (2011).

\section{MÉTODOS E TÉCNICAS}

Quanto aos objetivos específicos, a pesquisa tem caráter descritivo e exploratório, buscando descrever as características da população ou fenômeno e proporcionar maior familiaridade com o problema, respectivamente. Quanto ao delineamento, segundo Cervo e Bervian (1983) a pesquisa é bibliográfica, isto é, procura explicar um problema a partir dos referenciais teóricos publicados em documentos, que buscam explicar pelo conhecimento e análise as contribuições sociais e científicas do passado a respeito de determinado tema ou assunto. Em relação à natureza de pesquisa, é qualitativa, ou seja, segundo Denzin e Lincoln (2006), a pesquisa qualitativa envolve a coleta de uma variedade de materiais empíricos, estudos de caso, experiências pessoais, introspecção, entre outras coisas, dessa forma, a pesquisa envolve também uma ampla variedade de práticas interpretativas interligadas, como fundamento da compreensão do assunto a ser abordado. Há o entendimento pela natureza qualitativa de uma visão diferente dos fatos, havendo também a necessidade de mais de uma prática interpretativa em qualquer estudo.

\subsection{Teoria da Contingência e Ambiente Externo, Componentes do Modelo Proposto}

De acordo com Guerreiro et al. (2006), a teoria da contingência busca explicar o processo de mudança organizacional e suas interdependências com os fatores ambientais, relacionados à mudança, à complexidade do ambiente externo, às variáveis que induzem o processo de mudança, às forças e fraquezas da organização, aos valores, às habilidades e atitudes dos membros da organização, entre outros aspectos relativos aos processos e tecnologia por ela empregados. Ainda, para Guerreiro et al. (2006) implementar ou abandonar determinado sistema gerencial pode ser justificado pela melhor compreensão dos aspectos dessa teoria.

De acordo com a literatura, o ambiente externo é composto pelo ambiente setorial ou competitivo e, envolvendo esse ambiente competitivo, está o macro ambiente. O macroambiente é composto pelos fatores: Sociais; Econômicos; Político/Legais e Tecnológicos (Wrigth, Kroll \& Parnell, 2010), (Batteman \& Snell, 2006).

Para Collis e Ghemawat (2000) o ambiente competitivo popular é baseado nas 5 forças de Porter (1986): grau de rivalidade dos concorrentes, ameaça dos substitutos, poder dos compradores, a ameaça de entrada e poder dos fornecedores.

A partir da caracterização do ambiente externo, o modelo de ADO proposto se iniciará por meio de um questionário com perguntas específicas sobre o macro ambiente e seus fatores e, posteriormente, sobre o ambiente competitivo ou setorial, de forma a fazer uma "varredura ambiental" 
(Batteman \& Snell, 2006), que significa a busca e seleção de informações sobre o ambiente.

No ambiente macro é possível fazer três ensaios de informações, de forma a apresentar informações para três cenários possíveis de impacto na organização. No ambiente competitivo ou setorial, mais próximo da empresa e menos mutável em relação ao macro ambiente, há apenas um ensaio.

O questionário referente ao macro ambiente está ponderado de forma que todos os fatores tenham o mesmo peso no final, independente da quantidade de perguntas, o mesmo acontecendo com o questionário do ambiente competitivo ou setorial. $\mathrm{O}$ avaliador preenche ao início do ciclo de avaliação, com base nas informações que tiver disponível os fatores do macro ambiente optando pela seguinte escala em cada questão: 1 - não vai acontecer - $0 \%$ de chance; 2 - pode não acontecer - $25 \%$ de chance; $3-50 \%$ de chances de acontecer; 4 - pode acontecer - $75 \%$ de chance; 5 - vai acontecer - $100 \%$ de chance; 0 - não se aplica (quando não interfere no setor da empresa). Na Figura 3 estão disponíveis os fatores, as questões e a disposição dos cenários.

\begin{tabular}{|c|c|c|c|}
\hline CENÁRIOS & $\mathbf{A}$ & B & C \\
\hline $\begin{array}{l}\text { ECONÔMICO } \\
\text { Tendência de crescimento do PIB. } \\
\text { O governo irá reduzir os juros. } \\
\text { A inflação irá diminuir. } \\
\text { A taxa de câmbio tende a cair. } \\
\text { A oferta de crédito irá aumentar. } \\
\text { A inadimplência tende a cair. } \\
\text { O nível de emprego irá crescer. } \\
\text { O rendimento médio real irá subir. } \\
\text { A produção da indústria de transformação irá crescer. } \\
\text { A atividade do comércio/serviços irá subir. }\end{array}$ & & & \\
\hline $\begin{array}{l}\text { SOCIAL } \\
\text { Há tendência de crescimento do público alvo para o setor. } \\
\text { Espera-se comportamento melhor de demanda no próximo período sazonal em relação ao imediatamente anterior. } \\
\text { Há novas tendências de moda que deverão impactar positivamente ao setor. } \\
\text { Será mais fácil buscar profissionais qualificados no próximo período. } \\
\text { Não há tendência de impactos negativos ecológicos na atividade. } \\
\text { Tendência de mais mulheres assumindo cargos de chefia nos próximos períodos. } \\
\text { Mais pessoas tendem a migrar/emigrar para o entorno da empresa. }\end{array}$ & & & \\
\hline $\begin{array}{l}\text { POLÍTICO } \\
\text { Não há tendência de interferência regulacional do governo no setor (qualquer esfera). } \\
\text { Há leis no congresso que se votadas podem melhorar as condições do setor. } \\
\text { O governo atual é favorável aos interesses do setor. } \\
\text { O setor apresenta um sindicato representativo junto às forças políticas do país. }\end{array}$ & & & \\
\hline $\begin{array}{l}\text { LEGAL } \\
\text { O setor/empresa não tem passivo trabalhista, dessa forma, não precisa se preocupar com isso. } \\
\text { Não há pendência judicial, cujo resultado afete futuramente o setor ou a empresa. }\end{array}$ & & & \\
\hline $\begin{array}{l}\text { TECNOLÓGICO } \\
\text { A tendência da tecnologia relacionada ao setor da empresa é manter-se estável. } \\
\text { A tendência para a busca de conhecimento no setor é de manter-se de fácil acesso, e a custo baixo. } \\
\text { Os gastos em pesquisa no setor permanecerão acessíveis no próximo período. }\end{array}$ & & & \\
\hline SOMATÓRIO DOS PONTOS & & & \\
\hline
\end{tabular}

Figura 3 - Assertivas para a Criação do Cenário de Macro Ambiente PME

Após a atribuição dos pontos obtidos na Figura 3, é feita a confrontação com o tipo de cenário a ser enfrentado pela organização, de acordo com a pontuação: Cenário Pessimista: de 0 a 34 pontos;
Cenário Neutro: de 35 a 70 pontos; e Cenário Otimista: de 71 a 100 pontos. Ainda, há a pontuação por fator que indicará qual é o fator que deverá contribuir mais ou menos para o sucesso da organização. 
Modelo de Avaliação de Desempenho Organizacional para Pequenas e Médias Empresas

A seguir, na Figura 4 estão as assertivas relacionadas ao ambiente competitivo ou setorial, que utiliza, para cada força apresentada a seguinte escala:
1- discordo totalmente; 2- discordo em parte; 3- não discordo nem concordo; 4- concordo em parte; 5concordo totalmente; 0- não se aplica.

\begin{tabular}{|c|c|}
\hline FORÇA & PONTOS \\
\hline $\begin{array}{l}\text { BARREIRAS AOS NOVOS ENTRANTES } \\
\text { Empresas de qualquer porte podem entrar no setor. } \\
\text { No setor não há fidelidade de marca por parte dos clientes. } \\
\text { Não é necessário muitos investimentos para entrar no setor. } \\
\text { O custo da mudança para o cliente é muito baixo. } \\
\text { Baixo investimento em tecnologia, não existe patente. } \\
\text { Fácil criar canais de distribuição, local de fácil acesso aos clientes. } \\
\text { Não há exigências do governo que beneficiam empresas existentes ou limitam a entrada de novas empresas. } \\
\text { Empresas estabelecidas têm pouca experiência no negócio ou custos altos. } \\
\text { Não há conflito entre os concorrentes já estabelecidos e os futuros concorrentes. } \\
\text { O mercado não está saturado. }\end{array}$ & \\
\hline $\begin{array}{l}\text { CONCORRENTES } \\
\text { Existe grande número de concorrentes, com relativo equilíbrio em termos de tamanho e recursos. } \\
\text { O setor onde se situa o negócio mostra lento crescimento. Uns prosperam em detrimento de outros. } \\
\text { Custos fixos e de estocagem altos e pressão no sentido do vender o máximo para cobrir estes custos } \\
\text { Forte briga de preços entre os competidores. } \\
\text { Os concorrentes fazem ofertas de emprego aos funcionários das outras companhias. } \\
\text { Os produtos e serviços são muito parecidos entre os comercializados pelos concorrentes. } \\
\text { Custo da mudança alto para os concorrentes saírem do negócio. }\end{array}$ & \\
\hline $\begin{array}{l}\text { SUBSTITUTOS } \\
\text { Muitos produtos de empresas não concorrentes podem substituir com satisfação os produtos da empresa. } \\
\text { Produtos/serviços substitutos têm custos mais baixos que os das empresas existentes no negócio. } \\
\text { A tecnologia dos produtos substitutos está em estágio de crescimento, enquanto o setor de atuação está estagnado. } \\
\text { Empresas que vendem produtos substitutos vendem também produtos concorrentes da empresa. }\end{array}$ & \\
\hline $\begin{array}{l}\text { CLIENTES } \\
\text { O poder de barganha dos clientes é alto pelo seu volume de compras e seu porte. } \\
\text { Produto/serviço vendido pela empresa representa muito nos custos dos clientes ou de suas compras. } \\
\text { Produtos/serviços que os clientes compram são padronizados e sem diferenciação. } \\
\text { Clientes não têm custos de mudança, fácil trocar de fornecedor. } \\
\text { Há ameaça dos clientes virem a produzir seu próprio insumo não necessitando futuramente dos produtos da empresa. } \\
\text { Produto/serviço vendido pela empresa existente não é essencial para melhorar os produtos do comprador. } \\
\text { Clientes são muito bem informados sobre preços e custos do setor. } \\
\text { Clientes trabalham com margens de lucro achatadas. }\end{array}$ & \\
\hline $\begin{array}{l}\text { FORNECEDORES } \\
\text { O poder de barganha dos fornecedores é alto pelo seu porte e volume de entrega requerendo lote mínimo de compra. } \\
\text { Produtos/serviços adquiridos pelas empresas existentes não são facilmente substituídos por outros. } \\
\text { Empresas existentes no negócio não são clientes importantes para os fornecedores. } \\
\text { Materiais/ serviços adquiridos dos fornecedores são importantes para o sucesso dos negócios no setor. } \\
\text { Os produtos comprados dos fornecedores são diferenciados. } \\
\text { Existem custos de mudança significativos para trocar de fornecedor. } \\
\text { Ameaça permanente de os fornecedores entrarem no negócio do setor. }\end{array}$ & \\
\hline SOMATÓRIO DOS PONTOS & \\
\hline
\end{tabular}

Figura 4 - Assertivas para o Levantamento das Forças do Ambiente Competitivo.

A atribuição dos pontos da Figura 4 anterior levará a um computo do grau de intensidade das forças somadas no ambiente competitivo, que, de acordo com a pontuação poderá ser: de intensidade baixa: de 0 a 34 
Modelo de Avaliação de Desempenho Organizacional para Pequenas e Médias Empresas

pontos; de intensidade média: de 35 a 70 pontos; e de intensidade alta: de 71 a 100 pontos. Quanto maior a intensidade, mais hostil é o ambiente competitivo da empresa. A pontuação por força indicará o ponto de maior preocupação da empresa e o maior impacto dessa força no ambiente competitivo.

Para o impacto das dimensões do ambiente externo na organização, o autor deste estudo atribuiu $60 \%$ de peso para o macro ambiente e $40 \%$ de peso para o ambiente competitivo no impacto sobre o ambiente interno, para este ensaio, já que não há convenção a respeito dessa influência na literatura e a literatura afirma que o macro ambiente exerce poder superior sobre o ambiente competitivo e, consequentemente, sobre a organização.

\section{APRESENTAÇÃO E ANÁLISE DOS RESULTADOS}

\subsection{Indicador de Desenvolvimento Global - Enviroment (IDG-E)}

A proposta do IDG-E é apresentar um sistema de avaliação de desempenho organizacional que leve em consideração o peso do ambiente externo na avaliação interna, bem como, o peso das áreas internas que influenciam outras áreas dentro da organização, de acordo com o modelo proposto, de forma a deixar menos subjetiva possível a ponderação das áreas chaves do processo de avaliação. Dessa forma, o IDGE utiliza o aporte teórico do modelo MADE-O (Corrêa, 1986) como o principal modelo ou modelo base, dada a sua flexibilidade em atender às PMEs, conforme foi levantado nos aspectos metodológicos deste estudo; e adaptações com o BSC (Kaplan \& Norton, 1997), dada a relação de causa e efeito e pelo balanceamento dos objetivos de curto e de longo prazo, os resultados e os vetores desses resultados e o IPMS (Bititci et al., 1997), pelo constante monitoramento externo, ajudando a definir os indicadores internos ajudados pelo conceito trazido da Teoria da Contingência.

Para melhor adequação do modelo, as seguintes questões chaves sobre o modelo, apresentadas por Corrêa (1986), no referencial teórico deste estudo, serão respondidas a seguir: Para que? Para avaliação, gerenciamento e monitoramento; Para quem? Proprietários de PMEs e Funcionários; O que? Avaliação de desempenho organizacional com módulos ponderados pelo ambiente externo da organização; Como? Preenchimento de questionário prévio sobre o ambiente externo, análise dos módulos e hierarquização de indicadores; Quem? Proprietário e funcionários habilitados; Quando? De forma semestral ou anual.

Na Figura 5 estão os módulos e suas interrelações, baseadas no modelo Made-O (Corrêa, 1986).

\subsection{Definição e Tratamento dos Módulos, Principais Indicadores}

\subsubsection{Módulo de Recursos Humanos}

O módulo de Recursos Humanos lidará com o capital humano da PME e seus reflexos imediatos no módulo operacional como proposta do modelo. Este módulo sofrerá influência ponderada do ambiente externo advinda do fator social, relacionadas às condições de mão-de-obra, facilidade em encontrar mão de obra qualificada; e dos concorrentes que interferem da concorrência por mão-de-obra, bem como, pela busca de mão-de-obra treinada. Os principais indicadores de Recursos Humanos são: empregados/receita; empregados/custo e índice de felicidade no trabalho, conceito que traz a avaliação do grau de satisfação do funcionário em relação à organização, em relação à tarefa e em relação ao superior imediato.

\subsubsection{Módulo de Social Marketing}

O módulo de Social Marketing traz o conceito de Kotler e Armstrong (2007 p.532) de uma empresa engajada socialmente que toma decisões de marketing de acordo com o interesse e os desejos de seus consumidores, os requisitos da empresa e, interesses de longo prazo da sociedade. Dessa forma, as empresas que encaram os problemas sociais como uma oportunidade tendem apresentar relações interessantes com seus stakeholders. Este módulo influenciará o módulo de clientes e sofrerá a influência ponderada do fator social, relacionadas às tendências e costumes a serem monitorados; do ambiente político por meio das leis que podem influenciar as decisões de social marketing; e do ambiente legal, pois é necessário conhecer como obter isenção e benefícios legais da legislação em vigor. Os principais indicadores de social marketing são: produtos socialmente responsáveis / receita; produtos socialmente responsáveis / custo; redução tributária por produto social; e redução tributária por ação social. 


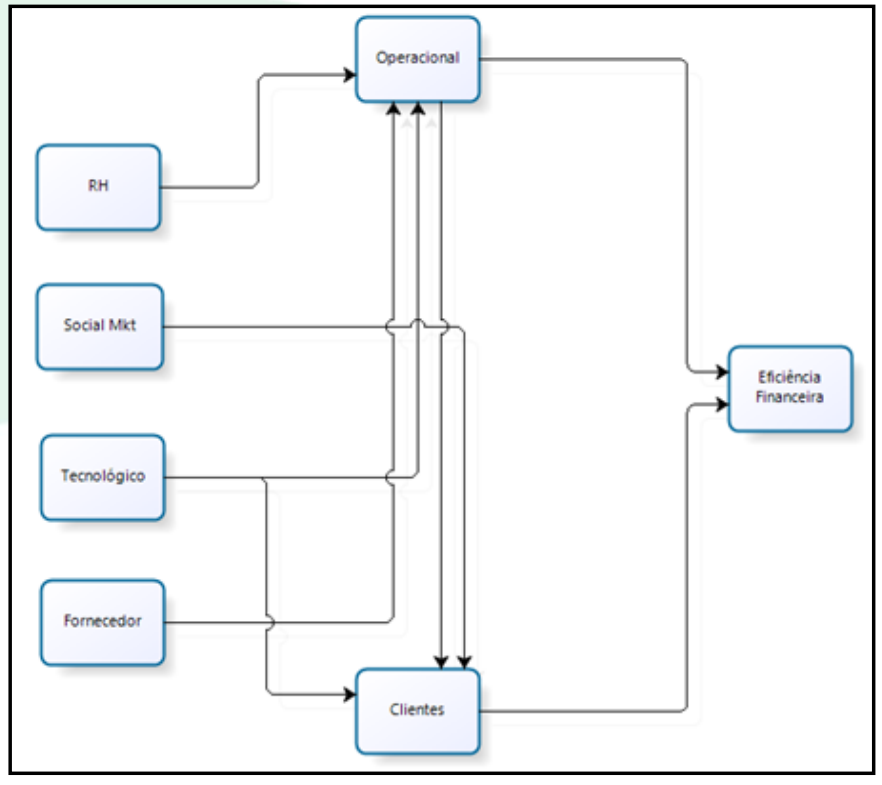

Figura 5 - Inter-relação entre os módulos propostos no IDG-E

\subsubsection{Módulo Tecnológico}

O módulo tecnológico aborda toda a tecnologia interna da organização e conhecimento (incluindo a gestão dele) e seu processo de melhoria e atendimento às necessidades dos clientes. Este módulo interfere tanto no módulo operacional, quanto no módulo clientes. O módulo recebe a interferência do fator político, por meio dos incentivos ou barreiras deles à inovação tecnológica, relacionados ao acesso à tecnologia; do fator tecnológico externo, no aprimoramento da tecnologia e conhecimentos existentes na área; e também da força dos substitutos, que obriga ao aprimoramento tecnológico e acompanhamento das tendências de forma a evitar a obsolescência e a troca dos produtos finais pelos de seus substitutos potenciais. Os principais indicadores deste módulo são: inovações/receita; inovações/custo.

\subsubsection{Módulo Fornecedor}

O módulo fornecedor lida com a relação com os fornecedores de matérias-primas ou serviços, sendo um ponto bastante importante e muitas vezes ignorado nas organizações. Este módulo influenciará diretamente o módulo operacional e receberá a influência do fator econômico, por determinar a lógica de preços, descontos, oferta; e do fator tecnológico, pois interfere na relação de redução de custos da empresa com melhores especificações. No ambiente competitivo, o reflexo da força fornecedores é de impacto direto, uma vez que se busca a relação ganha - ganha com o fornecedor. Os principais indicadores deste módulo são: pontualidade do fornecedor; inovação do fornecedor; desconto/redução de preço por fornecedor; novas demandas atendidas por fornecedor; redução de custo por fornecedor.

\subsubsection{Módulo Operacional}

O módulo operacional é um dos módulos de grande importância para a organização uma vez que recebe, de acordo com a proposta deste modelo, a influência ponderada de fatores e forças do ambiente externo e influência ponderada de módulos do ambiente interno ou organizacional. Para efeito meramente acadêmico, o autor estipulou impacto de $50 \%$ do ambiente externo e 50\% de impacto do ambiente interno. Do ambiente externo recebe a influência do fator econômico, por meio da determinação da necessidade ou não de turnos, máquinas, compra de matéria-prima, custos etc.; por sua vez, o fator social determina a tendência em volume de produção com a análise do potencial de demanda. Do ambiente competitivo, recebe a influência da força fornecedores por meio das especificações da matéria-prima, do preço, do custo e da qualidade da matéria-prima ou serviço oferecido. Do ambiente interno recebe a influência do módulo recursos humanos, através da motivação ao trabalho e da qualidade da mão-de-obra. Recebe a influência do módulo Tecnológico na melhoria dos conhecimentos sobre o processo, mensuração dos mesmos e novas tecnologias embarcadas nos equipamentos em uso pela empresa; e do módulo fornecedor na busca por uma matéria-prima ou serviço de qualidade. Ainda, o módulo operacional influencia nos módulos de clientes e de eficiência financeira. Os principais indicadores deste módulo são: receita/empregado; custo/empregado; qualidade/empregado; defeitos/equipamento e depreciação de máquinas e equipamentos. 


\subsubsection{Módulo Clientes}

Outro módulo de bastante importância na organização, também influenciado pelos ambientes interno e externo (igual proporção 50\%/50\%), está relacionado totalmente à satisfação do consumidor dos produtos da empresa. Do ambiente externo, sofre a influência do fator econômico, na determinação da demanda, nas condições de pagamento dos clientes etc. Do fator legal, das pendências judiciais junto aos clientes, nas reclamações dos clientes, nas relações com os órgãos de defesa do consumidor etc. No ambiente competitivo os impactos são das forças concorrentes, barreiras e clientes. Os concorrentes interferem na redução da fidelidade dos clientes; as barreiras na proteção do mercado da empresa; e os clientes na relação de fidelidade à empresa ou à marca da empresa e nas relações de parceria ou ganha a ganha com o cliente. Do ambiente interno, o módulo clientes recebe a influência ponderada do módulo social marketing, relacionada à tentativa de atender os clientes com produtos socialmente corretos, buscando agregar valor sem impactar em aumento de custos. Além disso, provocar ações que possam ser vistas pelos stakeholders como socialmente corretas, visando uma imagem positiva que atraia aumento de receita ou redução de custos. Recebe a influência ponderada do módulo tecnológico por oferecer as especificações aos clientes e contribuir para atender às suas demandas específicas. Ainda, recebe a influência ponderada do módulo operacional, responsável por atender todas as demandas do cliente, com qualidade, velocidade e presteza. O módulo clientes, por estar no final do ciclo de causa e efeito organizacional, impacta apenas no módulo de eficiência financeira. Os principais indicadores deste módulo são: receita/cliente; produtos/cliente; reclamações/cliente; novas demandas atendidas/cliente; e satisfação/cliente.

\subsubsection{Módulo Eficiência Financeira}

Este é o módulo de finalização do ciclo de avaliação e está relacionado aos indicadores financeiros da organização, uma vez que só há investimentos na organização se houver o retorno deles para o investidor. Ele não apresenta impacto do ambiente externo por ser um medidor de desempenho passado da organização. É influenciado pelos módulos operacional e clientes, que sofreram as influências de outros módulos e dos fatores e forças do ambiente externo. Dessa forma, uma boa gestão operacional e de clientes, garante um bom índice de eficiência financeira.

Este conceito, presente na fundamentação teórica deste estudo, apresenta a relação de todos os inputs necessários para gerar os outputs recomendáveis, de forma a avaliar se a empresa empregou bem todos os seus recursos (humanos, tecnológicos, de processo e de inteligência competitiva) de forma adequada. Os principais indicadores deste módulo são: receita/ativo; lucro/patrimônio líquido; custo/ativo; despesas gerais/ativo, todos extraídos do balanço patrimonial da organização. $O$ procedimento de dividir a receita líquida, os custos e as despesas pelo ativo total das próprias empresas e o lucro líquido pelo patrimônio líquido é minimizar o efeito da inflação nas comparações interanuais. Importante salientar que a divisão da receita líquida pelo total do ativo é um importante indicador de eficiência financeira chamado de Giro do Ativo Total, que indica o grau de eficiência que a empresa utiliza seus ativos para gerar vendas (Gitman, 2009). Esse indicador é do tipo quanto maior melhor. Outro indicador importante tem origem na divisão do lucro líquido pelo patrimônio líquido da empresa, chamado de Retorno Sobre o Capital Próprio e mede o retorno obtido sobre o investimento dos acionistas ordinários ou proprietários da empresa (Gitman, 2009). Também quanto maior melhor. Os indicadores deste módulo definem o indicador de eficiência financeira da organização. De posse desse indicador, fazer a análise comparativa com o estudo sobre Indicador Serasa Experian de Eficiência das PMEs, presente do arcabouço teórico deste estudo e nas referências, buscando diminuir o Gap em relação às empresas benchmarking.

\subsection{Avaliação Crítica do Modelo}

Utilizando os mesmos critérios de avaliação dos modelos apresentados nos métodos e técnicas o IDG-E será também avaliado, conforme a Figura 6. 
Modelo de Avaliação de Desempenho Organizacional para Pequenas e Médias Empresas

\begin{tabular}{|c|c|c|}
\hline CRITÉRIOS & IDG-E & EXPLICAÇÃO \\
\hline \multicolumn{3}{|l|}{ DUTRA } \\
\hline Personalização & (); & Pode atender às necessidades específicas da organização \\
\hline Ambiguidade & & Não há interpretação dúbia ou de duplo sentido \\
\hline Priorização & ; & Dá maior importância aos indicadores financeiros \\
\hline Flexibilidade & ;) & É flexível, pode ser usado em qualquer organização que vise fins lucrativos. \\
\hline Conhecimento & (); & $\begin{array}{l}\text { Nas PMEs é maior a interação com o modelo dada a importância dos resultados das pessoas } \\
\text { no processo. }\end{array}$ \\
\hline Aperfeiçoamento & (:) & $\begin{array}{l}\text { Há aperfeiçoamento pela troca de feedback constante e pela mudança do ambiente afetando } \\
\text { os processos da organização. }\end{array}$ \\
\hline \multicolumn{3}{|l|}{ GARENGOET AL. } \\
\hline Alinhamento & (); & $\begin{array}{l}\text { Apesar de não muito comum nas pequenas empresas, o modelo ajuda o administrador a } \\
\text { planejar melhor seus objetivos e metas, com base no entendimento do ambiente externo. }\end{array}$ \\
\hline Desenvolvimento & (:) & O modelo auxilia no desenvolvimento dos objetivos e estratégias. \\
\hline Stakeholders & ; & $\begin{array}{l}\text { O modelo tem o foco nos principais stakeholders: proprietário, funcionários, clientes e } \\
\text { fornecedores. }\end{array}$ \\
\hline Medidas Ñ Financeiras & (); & O modelo tem algumas medidas não financeiras. \\
\hline Adaptabilidade & (:) & É o modelo que tem maior grau de adaptação aos contextos interno e externo. \\
\hline Orientação Processo & (;) & Há coordenação de processos inter áreas na empresa. \\
\hline Detalhamento & (-) & As medidas abrangem todas as áreas da organização. \\
\hline Abrangência & (); & Toda a organização é objeto da avaliação. \\
\hline Causa / Efeito & (); & Há relação de causa e efeito entre os objetivos estratégicos e operacionais. \\
\hline Simplicidade & (); & $\begin{array}{l}\text { A metodologia é bastante simples para ser compreendida pelo proprietário e pelos } \\
\text { funcionários da PME. }\end{array}$ \\
\hline \multicolumn{3}{|l|}{ CORRÊA } \\
\hline Abrangente & (2) & Apresenta todas as dimensões que afetam o desempenho da empresa. \\
\hline Histórico & ;) & Apresenta histórico para Benchmarking e também é desenvolvido para avaliação semestral. \\
\hline Comparativo & ;) & Um ponto forte é ser comparativo aos demais concorrentes e setor macro de atividade. \\
\hline Causa / Efeito & (-) & Há forte relação entre as áreas principais e suas áreas de influência. \\
\hline Antecipação & (); & Pode-se trabalhar nas causas dos problemas. \\
\hline
\end{tabular}

Atende Totalmente $:-$ - Atende Parcialmente $:-$ - Negativos $;(-)$

Figura 6 - Avaliação Crítica das Metodologias Apresentadas no Estudo

Percebe-se que o indicador proposto é robusto para o propósito de uma PME, apresentando como pontos a serem melhorados no sistema a priorização dos indicadores do sistema, que na visão do autor, não é de vital importância, uma vez que as necessidades das PMEs são diferentes, conforme pôde ser observado no arcabouço teórico, em razão da forte tendência do proprietário querer ver resultados em curto prazo. Outro ponto de melhoria é a relação com os stakeholders, que na visão do autor pode ser melhorada com o contínuo crescimento sustentado da organização.

Além disso, o modelo resolve também alguns problemas das PMEs levantados por Leone (1999), citada por Ricci e Escrivão Filho (2010), como a ausência de planejamento formal e a estratégia intuitiva e pouco formalizada, do ponto de vista das especificidades organizacionais; nas especificidades decisionais, resolve o problema da tomada de decisão intuitiva e o trabalho em horizonte temporal curto. Resolve a ausência de dados quantitativos para a avaliação. Do ponto de vista das especificidades individuais, melhora a questão da onipotência do proprietário dirigente, auxilia na relação entre o patrimônio social e pessoal e ajuda na propensão a riscos melhor calculados. 


\section{CONSIDERAÇÕES FINAIS}

Neste trabalho, objetivou-se propor um modelo de ADO para PMEs, partindo-se do referencial teórico de diversos modelos e suas respectivas comparações com base nos critérios de três importantes autores para avaliação de ADO.

Conforme pôde ser evidenciado, os principais modelos de ADO mais consultados na literatura não apresentam em sua estrutura uma adaptabilidade interessante para as PMEs, dada as especificidades destas organizações, amplamente explicitadas no contexto deste estudo.

O Modelo MADE-O proposto por Corrêa (1986) foi o modelo, que segundo os critérios de três diferentes autores, melhor se enquadrou para as necessidades das PMEs. Por conta disso, foi utilizado como base para a criação da proposta do modelo apresentado neste estudo, com adaptações dos modelos BSC (Kaplan \& Norton, 1992) e IPMS (Bititci et al., 1997).

O Modelo chamado de Indicador de Desempenho Global - Enviroment (IDG-E) tem como principal diferencial, além da base dos modelos citados anteriormente, a avaliação do ambiente externo e interno com pesos ponderados nos módulos de ADO. Esse aspecto ajuda a organização a melhor planejar suas estratégias e objetivos, bem como, flexibilizar o desempenho organizacional, uma vez que a mudança ambiental provocará a flexibilização dos objetivos e metas dentro da empresa numa relação de causa e efeito. Isso permite ao administrador mudar rapidamente o foco para as metas, objetivos e desempenhos mais importantes rapidamente, do que continuar dando importância a objetivos, metas e desempenhos e menor importância dada à mudança de contexto ambiental.

Como a PME é caracterizada por ter poucos processos e pessoas, a pequena quantidade de indicadores de desempenho é outro aspecto positivo. Submetido à avaliação dos critérios apresentados pelos três autores, o modelo se mostrou bastante factível para uso nas PMEs.

Como principal limitação, o modelo proposto não foi testado em nenhuma PME, de forma que as contribuições deste estudo são apenas teóricas.

Outro aspecto importante está relacionado aos pesos dados para o ambiente externo entre o macro ambiente e ambiente competitivo, bem como, os pesos internos dados pela influência entre os módulos. Não há estudos que comprovem tais pesos e influências nas organizações, dessa forma, os pesos foram dados a critério do autor com base nas referencias deste estudo.

Empresas que não possuírem balanço patrimonial e demonstração de resultados não poderão auferir o resultado de eficiência financeira.

Como sugestão para estudos futuros, seria interessante a aplicação do modelo proposto em PMEs e o efetivo teste de sua eficácia.
Além disso, em razão dos pesos dos ambientes citados anteriormente serem dados de forma subjetiva, seria importante a realização de uma Pesquisa Delphi com especialistas, para que houvesse um consenso a respeito de quais são os impactos proporcionais do ambiente externo no ambiente interno e quais seriam as áreas cujos pesos dos impactos são mais importantes, umas sobre as outras.

\section{REFERÊNCIAS}

Amaru, M. Teoria geral da administração: da revolução urbana à revolução digital. São Paulo: Atlas, 2005.

Batteman, T. S.; Snell, S. Administração: novo cenário competitivo. 2.ed. - São Paulo: Atlas, 2006.

Bortoluzzi, S. C.; Vicente, E. F. R.; Ensslin, S. R.; Ensslin, L. Práticas de Avaliação de Desempenho Organizacional em Pequenas e Médias Empresas: Investigação em uma Empresa de Porte Médio do Ramo Moveleiro. In: IV Encontro de Estudos de Estratégia da Anpad. Recife, 2009.

Cervo, A. L.; Bervian, P. A. Metodologia Científica: para uso dos estudantes universitários. São Paulo: MacGraw-Hill do Brasil, 1983.

Collis, D.; Guemawat, P. Mapeando o Cenários dos Negócios. In:Guemawat, P.A Estratégia e o Cenário dos Negócios: Texto e Casos. PortoAlegre: Bookman, 2000.

Cunha, J. A. C. Avaliação de Desempenho e Eficiência em Organizações de Saúde. Tese (Doutorado em Administração) - Departamento de Administração da Faculdade de Economia, Administração e Contabilidade. São Paulo: Universidade de São Paulo, 2011.

Corrêa, H. L. O “Estado da arte” da avaliação de empresas estatais. Tese (Doutorado em Administração) - Departamento de Administração da Faculdade de Economia, Administração e Contabilidade. São Paulo: Universidade de São Paulo, 1986.

Denzin, N. K.; \& Lincoln, Y. S. A disciplina e a prática da pesquisa qualitativa. NK Denzin, YS Lincoln \& cols.(Orgs.), O planejamento da pesquisa qualitativa: teorias e abordagens, 2006. p.15-41.

Dutra, A. Metodologia para Avaliar e Aperfeiçoar o Desempenho Organizacional: incorporando a dimensão integrativa à MCDA ConstrutivistaSistêmico-Sinergética. Tese de Doutorado, Programa de Pós-Graduação em Engenharia de 
Produção, Universidade Federal de Santa Catarina, Florianópolis, 2003.

Garengo, P.; Biazzo, S.; Bititci, U. S. Performance measurement systems in SMEs: A review for a research agenda. International Journal of Management Reviews, v. 7, n. 1, 2005. p.25-47.

Gitman, L. J. Princípios de administração financeira. 12. ed. São Paulo: Person Prentice Hall, 2009.

Guerreiro, R.; Pereira, C.A.; Rezende, A.J. Em busca do entendimento e da formação dos hábitos e das rotinas da contabilidade gerencial: Um estudo de caso. Revista de Administração Mackenzie. v. 7 , 2006. n. 2.

Jamil, C. M.; Mohamed, R. Performance Measurement System (PMS) In Small Medium Enterprises (SMES): A Practical Modified Framework. World Journal of Social Sciences.Vol. 1.No. 3. July 2011. Pp. 200-212

Kaplan, R. S.; Norton, D. P. A Estratégia em Ação Balanced Scorecard. 7. ed. Rio de Janeiro: Campus, 1997.

"Using the Balanced Scorecard as a Strategic Management System", Harvard Business Review (jan./feb, 1996).

Kotler, P.; Armstrong, G. Princípios de Marketing. 12. Ed. São Paulo: Pearson Prentice Hall, 2007.

Macedo, M. A. S.; Silva, F. F.; Santos, R. M. Análise do mercado de seguros no Brasil: Desempenho Organizacional das Seguradoras no ano de 2003. Dez. 2006. Disponível em: <http://www.eac.fea.usp.br/cadernos/completos/ed comemor4/marcelo_fabricia_rodrigo_pg88a100.pdf > Acesso em: 27 set. 2011.
Meimand, M.; Cavana, R. Y.;Laking, R. Using DEA and Survival Analysis for Measuring Performance of Branches in New Zealand's Accident Compensation Corporation.Journal of Operational Research Society. v. 53, n. 3, p. 303-313, 2002. Disponível em: <http://www.palgravejournals.com/jors/journal/v53/n3/pdf/2601291a.pdf $>$ Acessado em 29 set. 2011.

Nørreklit, H. The balance on the balanced scorecard - a critical analysis of some of its assumptions.Management Accounting Research, v. 11, 2000. p. 65-88.

Porter, M. Estratégia Competitiva: Técnicas para Análise de Indústrias e da Concorrência, Rio de Janeiro, Campus, 1986.

Ricci, G. L.; Escrivão Filho, E. Análise dos Indicadores de Medição de Desempenho em Pequenas e Médias Empresas do Setor Hoteleiro. In: XII SEMEAD Seminários em Administração. São Paulo, 2010.

Serasa Experian. Porte das organizações (2010). Disponível em: <http://www.serasaexperian.com.br/solucoes/credit rating/creditrating_perguntaserespostas.htm?frompa ge=empresa $>$ Acesso em 30 out. 2012.

. Indicador de Eficiência Empresarial de PMEs (2011). Disponível em: <http://www.serasaexperian.com.br/release/noticias /2011/noticia_00593.htm> Acesso em: 04 dez. 2012.

Wright, P.; Kroll, M.J.; Parnell, J. Administração Estratégica: Conceitos. 1. Ed.- 11. Reimpr.-São Paulo: Atlas, 2010. 